Article

\title{
Insights for Sustainability of Smartphone Business: Understanding Customer Switching Behavior in Smartphone Services
}

\author{
Chang-Gyu Oh and Jongpil Park * \\ Department of Management Information Systems, School of Business, Kyungnam University, \\ Changwon 51767, Korea; cgoh@kyungnam.ac.kr \\ * Correspondence: jpark@kyungnam.ac.kr
}

Received: 27 November 2019; Accepted: 30 January 2020; Published: 3 February 2020

check for updates

\begin{abstract}
Competition in smartphone market has been fierce, and customers' switching has become a primary concern for the success of smartphone businesses. Nonetheless, research on customer switching behavior regarding smartphones is still under investigation. The purpose of this study is to examine how social factors affect users' smartphone switching intention and how customer rational and emotional factors moderate the customers' switching behavioral intention. In an attempt to understand the switching behavior of smartphone users, this study develops and tests a model drawn from social factors (e.g., media and peer influence), customer rational factors (e.g., switching experience and confidence in decision making), and customer emotional factors (e.g., anticipated regret and alternative attractiveness). The model is tested with data collected from 302 smartphone users. The results of structural equation modeling analysis demonstrate that, when customers make switching decision, both media influence and peer influence affect behavioral switching intention. Further, this study also revealed that customer rational and emotional factors moderate the effects of media influence and peer influence toward customers' switching intention. Overall, this study enhances the omnidirectional understanding of the switching behavior of smartphone users and can help smartphone companies in fierce competition to lead to sustainable growth.
\end{abstract}

Keywords: switching behavior; media influence; peer influence; switching experience; confidence in decision making; anticipated regret; alternative attractiveness

\section{Introduction}

Smartphones are increasingly potent individual devices that provide new ways of communication, searching and sharing information, and excitement. As such, smartphones have become a popular issue among consumers, and the smartphone market has grown exponentially. Due to technology advances, individuals can easily access smartphone alternatives. Paradoxically, this phenomenon has encouraged customers to switch to newer smartphones. In particular, for consumers, switching their smartphone OS platform is the most important issue. As a result, the competition in the smartphone market has been fierce, and customer switching has become a primary concern for the success of any smartphone business [1,2].

In this sense, research have begun to examine the switching behavior of smartphone consumers. However, most of research related to smartphone switching is mainly concerned with the technology attributes related to functionality, such as operating system (i.e., iOS, and Android), user interface, and mobile cellular network infrastructure [1]. However, consumers switch smartphones both functional but nonfunctional reasons [3]. Nonetheless, little is known about the nonfunctional switching reasons of smartphone consumers. 
Although some empirical studies have traced nonfunctional switching factors, which are drawn from the technology acceptance model (TAM) or the unified theory of acceptance and use of technology (UTAUT), most of these studies have chosen to center on individual factors. However, the fundamental argument is that individuals from beliefs about information technologies inside a milieu of impacts exuding from both individual and social contexts [4]. Nonetheless, extant studies have not examined how social factors jointly shape individual beliefs about information technologies. In particular, social factors play a very important role in the choice to switch smartphones because smartphone users generally decide to switch smartphones based on social context, such as media and peer influence. On the other hand, when consumers switch smartphones, they are affected by rational and emotional factors. As such, this study has an important research question: how do social factors affect users' smartphone switching intention, and how do customer rational and emotional factors control customers' switching behavior?

Therefore, the primary aim of this study is to examine the social factors that influence key individual beliefs about smartphone switching. Further, this study traces how customers' rational and emotional factors moderate switching behavioral intention. By identifying these various relationships, this study looks for the ways to ensure sustainable growth in the smartphone market.

\section{Theoretical Background}

\subsection{Customer Switching Behaviour}

Customer switching has been studied extensively in the field of management, marketing, and information systems. In particular, a significant number of studies have been examined the impact of consumer switching behavior $[5,6]$. These studies mainly focus on understanding why consumers decide to switch to other products or services. Among them, the factors that drive consumers to switch have received the most attention among researchers [7]. This is because these studies have high potential to offer more pertinent and practical suggestions to practitioners.

On the other hand, some theoretical bases give the conceptual frame for technology switching. Individual beliefs about technology use and switching are influenced by two dominant sources of influence-individual and social factors [8,9]. Among them, although individual factors are examined in a variety of studies associated with TAM and UTAUT, social factors have not been vigorously examined. As such, this study focuses on the influence of social factors that are key individual beliefs about consumer switching.

\subsection{Social Environment Factors: Informational Influences}

A basic tenet of consumer behavior theory holds that when consumers make purchase decisions, they use different types of information sources [5] (p. 376). Indeed, individual beliefs about technology use are influenced by primary information sources at varying distance from internal psychological processes. Specifically, research has identified that individual consumer behavior is embedded in social contexts and is thus susceptible to interactions with one's social environment. The social environment can be separated in sources of information influence, such as external and interpersonal source of information [8] (p. 659).

\subsubsection{External Source of Information: Media Influence}

External source of information refers to mass media, reports, expert opinions, and other impersonal information considered by adopters in making a rational acceptance decision [5] (p. 380). In general, consumers accept external information by reading articles related to a certain products or services in mass media. Consumers who seek external information look for factual and objective information about products or services. 
A preponderance of factual information about attributes should lead to more accurate predictive expectations about the future performance of the product or service [10]. Therefore, external information is also thought to play a role throughout the adoption, switching, and diffusion processes [11].

Indeed, research found that information received from external information such as media has an impact on individual behaviors [11,12]. For instance, Promotosh and Sajedul (2011) argued that mass media play a viable role as a great advertising communication instrument for passing on a message [13]. They found that media presentation has coordinated and solid relationships to consumer's buy choices notwithstanding of their age, instruction, and social status.

Further, a number of studies found that individuals' switching behavior are positively related to media influence, such as newspapers, journals, television, and the internet $[5,8,12]$. We therefore formulate the following hypothesis:

Hypothesis 1 (H1). External information influence (media influence) positively influences smartphone user switching intention.

\subsubsection{Interpersonal Source of Information: Peer Influence}

Interpersonal information refers to word-of-mouth influence by friends, colleagues, superiors, and other prior adopters known to the potential adopters [14] (p. 413). When making products or service choices, customers tend to rely on word-of-mouth of others more than on their own opinions. Even though information from other people is both subjective and evaluative, it does seem to have vicarious involvement [5]. Accordingly, the influence of interpersonal relations should be important in technology adoption [12].

In particular, individuals are in general uncomfortable with uncertainty and will tend to increase communication with own social networks [15]. Indeed, information influence by peers decreases the hazard of selection and vulnerability because it gives solid proof of the authenticity and suitability of the appropriation choice. Therefore, socially proximal referents are vital for the consumption of products or services [16].

As such, several studies empirically demonstrated that interpersonal influence affects the adoption of technology. Schmitz and Fulk (1991) and Fulk (1993) found that information is passed on by means of an individual's social networks $[17,18]$. Specifically, they empirically found and argued that individuals are influenced by other people's views. Therefore, a compelling message received from others is likely to influence one's technology use or switching.

In addition, Karahanna et al. (1999) found that interpersonal influence is very significant in potential adopters [15]. They revealed that peer opinions significantly affected one's felt pressures toward adopting IT. Similarly, since people use their smartphone for private purposes, change or switching is preferred when individuals find that the advice or pressure from peers results in higher switching intention. We therefore formulate the following hypothesis:

Hypothesis 2 (H2). Internal information influence (peer influence) positively influences smartphone user switching intention of smartphone.

\subsection{Moderating Role of Customer's Rational Factors}

In customers' switching environments, some factors should be considered as important factors by reflecting customers' rational decision making. Among them, switching experience and confidence in decision making are considerable factors influencing customer switching behavior. These factors can be a significant moderating role. 


\subsubsection{Switching Experience}

Switching experience refers to how many products or services customers have experienced. Hoffman and Novak (1996) argued that low experience users tend to have exploratory behavior, while highly experienced users tend to show goal-oriented behavior [19].

In smartphone switching situations, customers who have low switching experience tend to be satisfied with the smartphones they are using. Accordingly, they are less likely to switch smartphones and consequentially have low switching experience. Indeed, the users with low switching experience are not swayed by the experiences of their peers or word-of-mouth of colleagues. Therefore, the users with low switching experience are not strongly affected by the interpersonal source of information. Rather, they are influenced by mass media or other impersonal information.

On the other hand, customers with high switching experience tend to have a variety of unsatisfactory factors. Accordingly, they have a high frequency of smartphone switching. Therefore, the users with high switching experience often express their dissatisfaction with their friends or colleagues. As a result, peers around the users are encouraged to switch, and the users have a strong switching intention. We therefore formulate the following hypothesis:

Hypothesis 3a (H3a). The effect of external information influence (media influence) on switching intention will be moderated by users' switching experience.

Hypothesis $\mathbf{3 b} \mathbf{b} \mathbf{H} 3 \mathbf{b})$. The effect of internal information influence (peer influence) on switching intention will be moderated by users' switching experience.

\subsubsection{Confidence in Decision Making}

Another considerable factor is confidence in decision making. Confidence in decision making refers a consumer's rational belief that someone has done something correctly or incorrectly which can increase for correct decisions and decrease for error decisions [20] (p. 539). In other words, consumer confidence in decision making is decided by the degree to which an individual feels able and guaranteed in relations to his or her choices and behaviors [21].

Research has shown that confidence in decision making rely on the amount of information available. It implies that, with the increase in accessible information, customer confidence will increase. Tsai et al. (2008) found that individuals become more confident if more information is provided to them [22].

Particularly, in marketing literature, confidence in decision making was hypothesized to be an important moderator on customer switching intention. For example, customers who have high confidence in their decision making are very confident in their knowledge and information processing. In other words, they tend to have high external information processing. Therefore, they are affected by external sources of information drawn from television, newspapers, offline or online ads and commercial articles, etc. On the contrary, customers who have low confidence in decision making are less confident in knowledge and information processing. In other words, they are less capable of processing external information. Rather, they are likely to adopt information from friends and colleagues. As a result, individuals around the users are encouraged to switch, and consequentially, the users have a strong switching intention. We therefore formulate the following hypothesis:

Hypothesis 4a (H4a). The effect of external information influence (media influence) on switching intention will be moderated by user confidence in decision making.

Hypothesis $4 \mathbf{b} \mathbf{( H 4 b )}$. The effect of internal information influence (peer influence) on switching intention will be moderated by user confidence in decision making. 


\subsection{Moderating Role of Customer's Emotional Factors}

Customers' emotional factors should be also considered as important factors affecting customer switching behaviors. Among them, anticipated regret and alternative attractiveness are thoughtful factors to customer switching behaviors

\subsubsection{Anticipated Regret}

One emotional aspect is anticipated regret. Regret generally refers to a negative emotion as a result of decision making under uncertainty [23]. Specifically, Zeelenberg and Piters (2007) defined regret as a counterfactual emotion resulting from external comparisons [24]. Also, Zeelenberg (1999) also defined regret as "a negative, cognitively based emotion that we experience when realizing or imaging that our present situation would have been better had we acted differently" [25] (p. 355).

In the smartphone market, there exist a number of alternatives. Hence, sometimes smartphone users feel disappointed and "regret" on the chosen technology, and even switch to another alternative. Therefore, it is important to have a better understanding of what regret is and how regret affects user evaluation and behavior regarding the chosen technology [26]. Nonetheless, little is known about the moderating role of customers' anticipated regret. For example, when deciding among alternatives, an individual must assess the potential utility to be derived from each option [27]. After selecting a course of action, an individual may feel that the situation would be better had a forgone alternative been selected.

As such, anticipated regret is a significant moderating role in smartphone switching intentions. Specifically, consumers with high anticipated regret are able to have high switching intentions. In general, they trust interpersonal information from peers or acquaintances rather than impersonal information from external source of information. On the other hand, consumers with low anticipated regret tend to have a rational disposition. Generally, they are strongly influenced by factual and objective information provided by media channels.

Accordingly, since there will be moderating effects, we therefore formulate the following hypothesis:

Hypothesis 5a (H5a). The effect of external information influence (media influence) on switching intention will be moderated by anticipated regret.

Hypothesis $\mathbf{5 b} \mathbf{( H 5 b )}$. The effect of internal information influence (peer influence) on switching intention will be moderated by anticipated regret.

\subsubsection{Alternative Attractiveness}

Alternative attractiveness becomes one of the vital emotional factors in switching behavior. Alternative attractiveness refers that "the expected outcome of the alternative is better than the outcome achievable with the existing partner" [28] (p. 56). Basically, consumers who perceive high alternative attractiveness have more confidence in their decision-making choices. As such, customers who perceive high alternative attractiveness have high switching intention. This is because customers who perceive high alternative attractiveness always have high interests in other smartphones. In particular, they are very sensitive to advertising drawn from offline or online media, and they also are very sensitive about which new smartphones are released. Therefore, consumers who perceive high alternative attractiveness are affected well by external sources of information rather than internal sources of information.

Meanwhile, the users who perceive low alternative attractiveness have low switching intention. They tend to be affected by their friends or colleagues' recommendations, which will be a more direct stimulus to switch. Accordingly, since there will be moderating effects, we therefore formulate the following hypothesis: 
Hypothesis 6a (H6a). The effect of external information influence (media influence) on switching intention will be moderated by alternative attractiveness.

Hypothesis $\mathbf{6 b} \mathbf{( H 6 b )}$. The effect of internal information influence (peer influence) on switching intention will be moderated by alternative attractiveness.

Based upon the all of hypotheses, the research model is depicted in Figure 1.

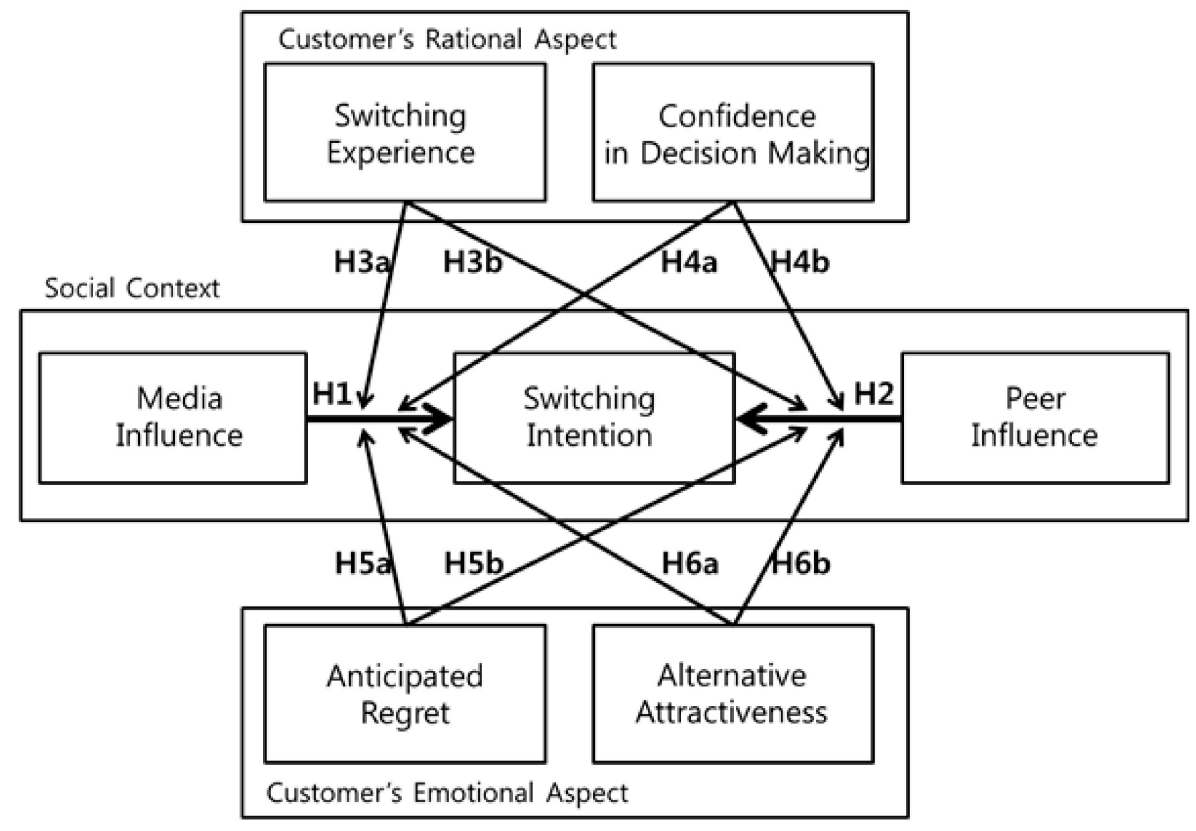

Figure 1. Research Model.

\section{Research Methodology}

\subsection{Data Collection}

The purpose of this study is to examine how social factors affect smartphone switching intention and how customer rational and emotional factors moderate customers' behavioral switching intention. The survey method is employed to test the proposed research and hypotheses. The research target of this study was smartphone users. We conducted several procedures for data collection.

First, a pilot study was conducted with 60 undergraduate students to assess and gauge the clarity of the questions. The participants provided detailed feedback through interviews. Based on this feedback, we reworded some items and reorganized the layout.

Second, the actual survey was conducted in the field. Specifically, the survey was conducted in the IT EXPO 2018, which is the largest ICT exhibition in Korea, from 5-7 September 2018. Basically, the participants are very interested in ICT devices, including smartphones. In other words, they may have significant experience in replacing smartphones. In addition, there are advantages to securing diverse age groups for the survey.

To ensure confidentiality, all participants were informed that their responses would remain anonymous and be used for academic purposes only. A total of 350 samples were collected. After discarding the incomplete questionnaires, the final usable sample was 302. Table 1 described the respondents' demographic statics. 
Table 1. Respondents' Profile.

\begin{tabular}{cccccccc}
\hline \multicolumn{2}{c}{ Variable } & $\mathbf{n}$ & $\mathbf{\%}$ & \multicolumn{2}{c}{ Variable } & $\mathbf{n}$ & $\mathbf{\%}$ \\
\hline \multirow{2}{*}{ Gender } & Male & 185 & 61.3 & Platform & Android & 180 & 59.6 \\
& Female & 117 & 38.7 & Type & iOS & 122 & 40.4 \\
\hline \multirow{4}{*}{ Age } & $20-30$ & 163 & 54.0 & Num. of & First & 9 & 3.0 \\
& $31-40$ & 52 & 17.2 & Smartphone & Second-third & 150 & 49.7 \\
& $41-50$ & 57 & 18.9 & (so far) & Fourth-fifth & 105 & 34.8 \\
& Over 51 & 30 & 9.9 & Over sixth & 38 & 12.6 \\
\hline
\end{tabular}

\subsection{Measurement}

The survey measurement for this study used multi-item scales adopted from previously validated scales and slightly modified to suit the context of the current study. Specifically, media influence was adapted from Yuen and Azree (2005), which was defined as the influence or pressure from media [29]. Four items asked the subject to mention how much they were affected by the related messages from each of the sources, such as TV program and/or advertisements.

Peer influence was adapted from Greszczuket al. (2018), which defined it as the influence or pressure from sources known to the smartphone user [30]. Four items were applied to measure how respondents perceive peer, family, and friends' influence on current smartphone issues.

Confidence in decision making measures was adapted from Bearden et al. (2001) and Hoffman and Elwin (2004) [21,31]. Five items were applied to measure the perception of confidence in decision making when they process the knowledge and information.

Anticipated regret measures were adapted from Conner and Abraham (2001) and Shih and Schau (2011) [32,33]. This construct was measured by four items-For example, if you switched your smartphone now and found out later that the other platform increase functionality, you will be disappointed with your decision.

In addition, alternative attractiveness measures were adapted from Sharma and Patterson (2000) and Ghazali et al. (2016) [34,35]. This construct was measured by four items-compared to Android (iOS), there is iOS (Android), with which I would probably be equally or more satisfied.

Finally, switching intention was measured with three items adapted from Shih and Hsu (2014) [36]. These items aimed at capturing the degree to which respondents would switch to another platform in the near future.

Faculty members with extensive experience in measurement scale development reviewed the results, and the initial version of measurement scales was refined based on their feedback. All items except switching experience were measured with a seven-point Likert scale from strongly disagree (1) to strongly agree (7).

\section{Data Analysis and Results}

\subsection{Reliability and Validity}

This section includes reliability and validity information. In this study, structural equation modeling (SEM) was used to test item reliability, convergent validity, and discriminant validity using SPSS Ver. 22 and LISREL 8.2 were used. Although the validity of the all constructs had been tested in previous studies, their validity was retested in this study. A confirmatory factor analysis (CFA) was conducted for all constructs. Similarly, the measurement model was revised by dropping items with low $(<0.50)$ factor loadings. High loading means that the shared variance between constructs and its measurement is higher than error variance [37]. As a result, all items were retained in this analysis. The final list of retained items is given in Table 2. As a result, the final CFA was acceptable.

The reliability of the constructs was examined with Cronbach's alpha shown in Table 2. All Cronbach's alpha was over 0.7, the cut-off for confirmatory research [38]. Therefore, individual item reliability is ensured in this study. 
The internal consistency of the scales was investigated using composite reliability (CR) values. Hair et al. (1998) suggested a threshold value of 0.7 [39]. All CR were higher than 0.7, which also indicated good internal consistency.

Convergent validity should also be examined when two indicators are used to measure the constructs. The convergent validity of the proposed constructs was evaluated through CFA. This validity could be ensured when factor loadings are higher than 0.7 , composite reliability of all constructs is higher than 0.7, and the AVE values are all greater than 0.5.

As a result, all factor loading values were equal to or larger than 0.70 and significant at $\mathrm{p}<0.001$. Based on high factor loadings and AVE evaluations, it could be judged that convergent validity for the measurement-scale items was achieved.

The existing literature (e.g., [40]) postulates that, in order to achieve discriminant validity, the correlation between a pair of concepts should be smaller than the square root of AVE value for each construct. As provided in the Tables 2 and 3, all of the correlations between a pair of constructs were smaller than the square root of AVE for each proposed concept, which supported strong discriminant validity.

Table 2. The results of the reliability and validity test.

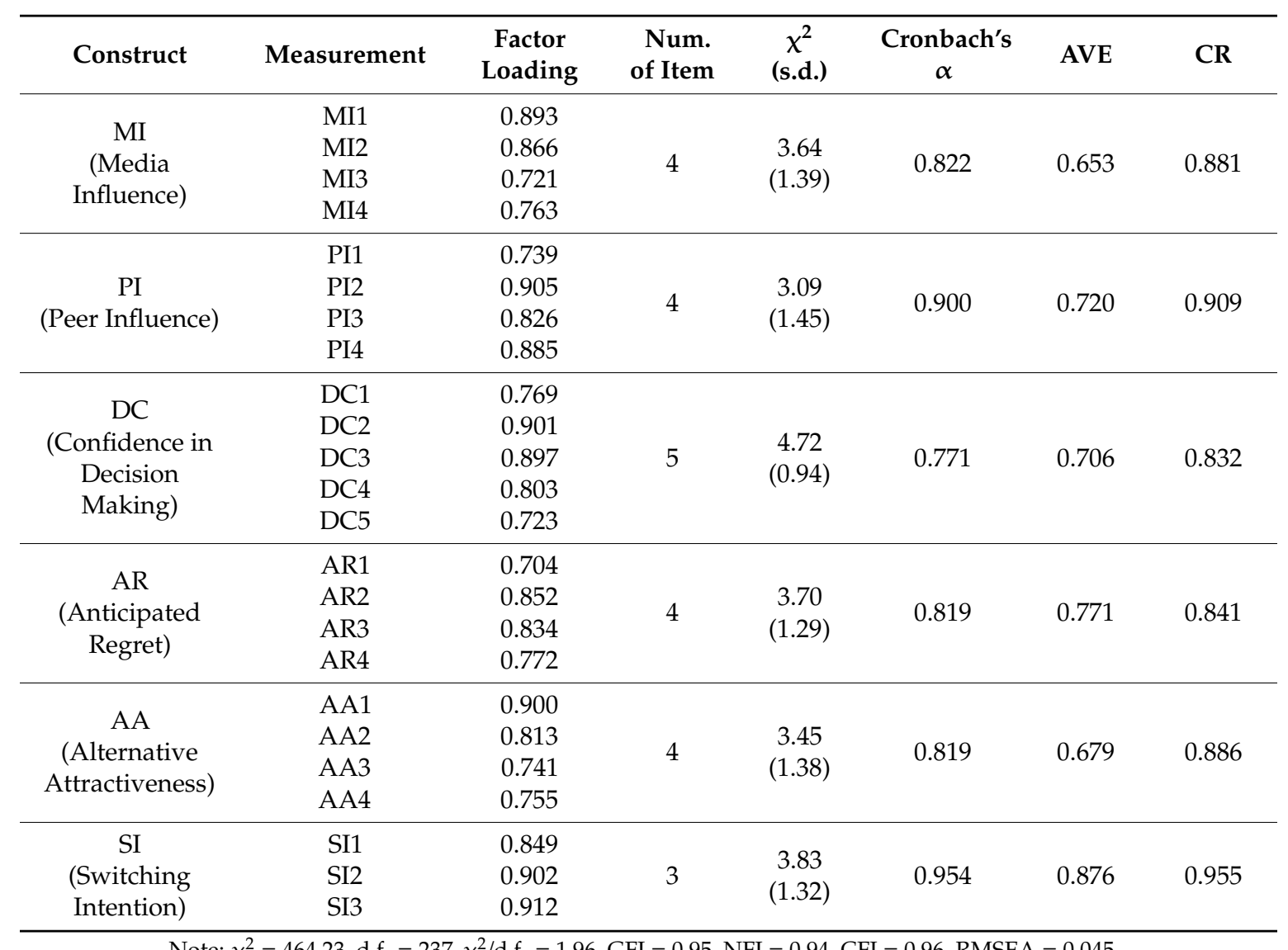

\subsection{Validation of Moderating Effect}

Using SEM, the general way of testing moderating effects is to split into two subgroups based on value of the candidate moderating variables from the full sample. Then, comparing the model fitting across groups, a $\chi^{2}$ difference test is conducted to assess the differences between two groups. If the model without any constraints is significantly better (smaller $\chi^{2}$ ) than the constrained one, the one group's coefficients differ from those of the other group. If the change of $\chi^{2}$ is significant, a moderating effect exists [41]. 
Table 3. Matrix among constructs ( $\Phi$ matrix).

\begin{tabular}{ccccccc}
\hline Construct & MI & PI & DC & AR & AA & SI \\
\hline MI & $\mathbf{0 . 6 5}$ & & & & & \\
\hline \multirow{2}{*}{ PI } & 0.24 & $\mathbf{0 . 7 2}$ & & & & \\
& $(0.08)$ & & & & & \\
\hline \multirow{2}{*}{ DC } & 0.11 & 0.13 & $\mathbf{0 . 7 1}$ & & & \\
& $(0.08)$ & $(0.08)$ & & & & \\
\hline \multirow{2}{*}{ AR } & 0.27 & 0.39 & -0.05 & $\mathbf{0 . 7 7}$ & & \\
& $(0.08)$ & $(0.07)$ & $(0.08)$ & & 0.68 & \\
\hline \multirow{2}{*}{ AA } & 0.26 & 0.40 & 0.12 & -0.54 & 0.88 \\
& $(0.08)$ & $(0.05)$ & $(0.08)$ & $(0.06)$ & & \\
\hline \multirow{2}{*}{ SI } & 0.35 & 0.42 & -0.17 & -0.37 & 0.52 & $(0.06)$ \\
& $(0.07)$ & $(0.06)$ & $(0.08)$ & $(0.07)$ & & \\
\hline
\end{tabular}

Note: ( ) is standard error, bold is AVE.

This method, however, does not verify whether the differences are determined by the direct effect such as error variances or moderating effect such as factor loadings of the dependent variables. This study's methodology was grounded in the work of Jöreskog, Sörbom (1993) and used in Im et al. (2008) and Oh (2012), which investigates more a rigid approach [42-44].

Specifically, in this methodology, the dataset is divided into groups, and the statistics from one are used to constrain models off the other. We generally test to find whether the changes of $\chi^{2}$ are statistically significant given the change in the degree of freedom. In order to test if the changes of $\chi^{2}$ were caused by the moderating variable, but this method compares four models for each moderating variable, such as from Models I to IV.

More specifically, Model I has all factor loadings constrained across the groups, and the error variances of the items for endogenous variables are constrained. Model II has the factor loadings free, but the error variances are constrained. Model III has both factor loadings and error variances are free. Model IV has factor loadings constrained, but error variances are free. For instance, if Model I and Model IV (or Model II and Model III) are different, it is caused by error variances in dependent variables. If Model I and Model II (or Model III and Model IV) are significantly different from each other, this is caused by the different factor loadings and path coefficients, which implies that there is a significant moderating effect. Thus, by comparing these models, the difference due to error variance can be separated from the difference from factor loadings and path coefficients.

The effects of switching experience, confidence in decision making, anticipated regret, and alternative attractiveness variables were tested following this procedure. Because the switching experience was a categorical variable, the groups were automatically divided into the switching experienced group and the non-experienced group. However, the other variables were a continuous variable, the groups were divided into high and low groups using the median as shown in Table 4.

As a result, Table 5 illustrates the comparisons of Models I, II, and III with fitting indices and $\Delta \chi^{2} / \Delta$ d.f. Model IV did not need to be compared because the comparison was redundant. As a result, as shown in Table 6 , the results of moderating effects and significant coefficients of the paths were determined.

Table 4. Moderating variable (median of the group).

\begin{tabular}{cccc}
\hline Construct & Median & t-Value & p-Value \\
\hline DC & 4.40 & 28.25 & $<0.000$ \\
AR & 3.25 & 28.25 & $<0.000$ \\
AA & 3.75 & 24.47 & $<0.000$ \\
\hline
\end{tabular}


Table 5. The results of moderating effects.

\begin{tabular}{cccccccccc}
\hline Variables & Model & $\chi^{2}$ & d.f. & $\chi^{2} /$ d.f. & GFI & NFI & CFI & RMSEA & $\Delta \chi^{2} / \Delta$ d.F. \\
\hline Whole sample & 82.78 & 41 & 2.02 & 0.99 & 0.93 & 0.95 & 0.042 & n/a \\
\hline \multirow{2}{*}{ Switching } & Model I & 244.77 & 97 & 2.52 & 0.97 & 0.85 & 0.81 & 0.124 & n/a \\
Experience & Model II & 222.99 & 94 & 2.37 & 0.98 & 0.86 & 0.90 & 0.122 & $7.26^{* * *(a)}$ \\
& Model III & 175.02 & 84 & 2.08 & 0.99 & 0.90 & 0.97 & 0.061 & $5.37^{* *(b)}$ \\
\hline Confidence in & Model I & 289.12 & 97 & 2.98 & 0.97 & 0.84 & 0.88 & 0.141 & n/a \\
Decision & Model II & 265.70 & 97 & 2.83 & 0.97 & 0.88 & 0.90 & 0.104 & $7.81^{* * *(a)}$ \\
Making & Model III & 163.34 & 84 & 1.94 & 0.97 & 0.96 & 0.91 & 0.091 & $9.68^{* *(b)}$ \\
\hline \multirow{2}{*}{ Anticipated } & Model I & 301.10 & 97 & 3.10 & 0.94 & 0.82 & 0.80 & 0.146 & $\mathrm{n} / \mathrm{a}$ \\
Regret & Model II & 287.72 & 97 & 3.06 & 0.95 & 0.85 & 0.86 & 0.144 & $4.46^{* * *(a)}$ \\
& Model III & 164.59 & 84 & 1.96 & 0.96 & 0.90 & 0.92 & 0.098 & $10.50^{* * *(b)}$ \\
\hline \multirow{2}{*}{ Alternative } & Model I & 289.12 & 97 & 2.98 & 0.97 & 0.84 & 0.88 & 0.141 & $\mathrm{n} / \mathrm{a}$ \\
Attractiveness & Model II & 264.66 & 97 & 2.82 & 0.97 & 0.89 & 0.90 & 0.101 & $8.15^{* * *(a)}$ \\
& Model III & 163.34 & 84 & 1.94 & 0.97 & 0.95 & 0.91 & 0.071 & $9.68^{* * *(b)}$ \\
\hline
\end{tabular}

(a) Difference between Model TypeI and Model Type II

(b) Difference between Model Type II and Model Type III

* Significant at $\alpha=0.05$ level; $* *$ Significant at $\alpha=0.01$ level; ${ }^{* * *}$ Significant at $\alpha=0.001$ level.

\subsection{Hypotheses Testing}

Structural equation modeling was employed to test proposed hypotheses. Tables 5 and 6 depict fit statistics, estimated path coefficients (all significant paths are indicated with an asterisk), and associated $\mathrm{t}$-value of the paths. The fit statistics indicate that the research model provides a good fit to the data shown as Table 5 (whole sample). $\chi^{2}$ is significant and all other statistics are within the range that suggests a good model fit. Table 6 shows the result of changes in standardized $\beta$ coefficients.

The findings from the whole sample model indicated that both peer influence and media influence exhibited strong impacts on user's smartphone switching intention. Specifically, peer influence posited a significant direct effect on switching intention $(\beta=0.59, \mathrm{t}=5.91)$, and the media influence also had a direct effect on switching intention $(\beta=0.53, t=5.69)$. Thus, the result supported Hypothesis 1 and Hypothesis 2, respectively.

Switching experience moderated also the effects of peer influence and media influence in the research model from the 7.26 in the $\Delta \chi^{2} / \Delta$ d.f. column in Table 5 . For the switching non-experienced group, media influence has a bigger effect on switching intention (MI $\rightarrow$ SI coefficients, 0.59 in Table 6) than the switching experienced group, which supports Hypothesis 5(a). However, peer influence has a bigger effect on switching intention (PI $\rightarrow$ SI coefficients, 0.75 in Table 6 ) for the switching experienced group than the switching non-experienced group. This supports Hypothesis 5(b).

Confidence in decision making moderated the effects of peer and media influence in the model (see 7.81 in the $\Delta \chi^{2} / \Delta$ d.f. column in Table 5). For users perceiving higher confidence in decision making, media influence has bigger effect on switching intention (MI $\rightarrow$ SI coefficients, 0.94 in Table 6) than those perceiving a lower confidence, which supports Hypothesis 6(a). However, peer influence has a bigger effect on switching intention (PI $\rightarrow$ SI coefficients, 0.58 in Table 6 ) for the low confidence in decision making than the high perceived self-confidence group. This also supports Hypothesis 6(b).

Anticipated regret moderated the effects of peer influence and media influence toward switching intention in the research model from the 4.46 in the $\Delta \chi^{2} / \Delta$ d.f. column in Table 5 . For users perceiving lower anticipated regret in using smartphone, media influence has bigger effect on switching intention $(\mathrm{MI} \rightarrow$ SI coefficients, 0.45 in Table 6 ) than those perceiving a higher anticipated regret, which supports Hypothesis 3(a). However, peer influence has a bigger effect on switching intention (PI $\rightarrow$ SI coefficients, 0.50 in Table 6) for the high perceived anticipated regret than the low perceived anticipated regret group. This supports Hypothesis 3(b). 
Alternative attractiveness also moderated the effects of peer and media influence in the model (see 8.15 in the $\Delta \chi^{2} / \Delta$ d.f. column in Table 5). For users perceiving higher alternative attractiveness, media influence has a bigger effect on switching intention (MI $\rightarrow$ SI coefficients, 0.59 in Table 6) than those perceiving a lower alternative attractiveness, which supports Hypothesis 4(a). However, peer influence has a bigger effect on switching intention (PI $\rightarrow$ SI coefficients, 0.69 in Table 6) for the low perceived alternative attractiveness than the high perceived alternative attractiveness group. This also supports Hypothesis 4(b).

Table 6. The changes in standardized $\beta$ coefficients.

\begin{tabular}{ccccccccccc}
\hline \multirow{2}{*}{ Path } & \multirow{2}{*}{$\begin{array}{l}\text { Whole } \\
\text { Sample }\end{array}$} & \multicolumn{3}{c}{ SE } & \multicolumn{2}{c}{ DC } & \multicolumn{2}{c}{ AR } & \multicolumn{2}{c}{ AA } \\
\cline { 3 - 10 } & & No $^{(\mathbf{a})}$ & Yes $^{(\mathbf{b})}$ & High $^{(\mathbf{c})}$ & Low $^{(\mathbf{d})}$ & Low $^{(\mathbf{e})}$ & High $^{(\mathbf{f})}$ & High $^{(\mathbf{g})}$ & Low $^{(\mathbf{h})}$ \\
\hline \multirow{2}{*}{$\mathrm{MI} \rightarrow \mathrm{SI}$} & \multirow{2}{*}{$0.53^{* *}(5.69)$} & $0.59^{* *}$ & $0.22^{* *}$ & $0.94^{* *}$ & $0.23^{* *}$ & $0.45^{* *}$ & $0.24^{* *}$ & $0.59^{* *}$ & $0.51^{* *}$ \\
& & $(17.53)$ & $(5.90)$ & $(9.99)$ & $(4.73)$ & $(10.34)$ & $(11.48)$ & $(17.09)$ & $(8.25)$ \\
\multirow{2}{*}{$\mathrm{PI} \rightarrow \mathrm{SI}$} & \multirow{2}{*}{$0.59^{* *}(5.91)$} & $0.22^{* *}$ & $0.75^{* *}$ & $0.26^{* *}$ & $0.58^{* *}$ & $0.23^{* *}$ & $0.50^{* *}$ & $0.22^{* *}$ & $0.69^{* *}$ \\
& & $(12.94)$ & $(15.81)$ & $(4.37)$ & $(7.52)$ & $(9.97)$ & $(13.33)$ & $(12.61)$ & $(10.45)$
\end{tabular}

(a) $\chi^{2} /$ d.f. $=1.49, \mathrm{GFI}=0.99, \mathrm{CFI}=0.98, \mathrm{RMSEA}=0.064$

(c) $\chi^{2} /$ d.f. $=1.76, \mathrm{GFI}=0.98, \mathrm{CFI}=0.96, \mathrm{RMSEA}=0.104$

(b) $\chi^{2} /$ d.f. $=1.67, \mathrm{GFI}=0.99, \mathrm{CFI}=0.91, \mathrm{RMSEA}=0.078$

(e) $\chi^{2} /$ d.f. $=1.63, \mathrm{GFI}=0.97, \mathrm{CFI}=0.94, \mathrm{RMSEA}=0.085$

(d) $\chi^{2} /$ d.f. $=1.94, \mathrm{GFI}=0.98, \mathrm{CFI}=0.93, \mathrm{RMSEA}=0.096$

(g) $\chi^{2} /$ d.f. $=1.42, \mathrm{GFI}=0.99, \mathrm{CFI}=0.98, \mathrm{RMSEA}=0.061$

(f) $\chi^{2} /$ d.f. $=1.48, \mathrm{GFI}=0.99, \mathrm{CFI}=0.92, \mathrm{RMSEA}=0.073$

(h) $\chi^{2} /$ d.f. $=1.94, \mathrm{GFI}=0.98, \mathrm{CFI}=0.95, \mathrm{RMSEA}=0.096$

* Significant at $\alpha=0.05$ level; ** Significant at $\alpha=0.01$ level.

\section{Discussion and Conclusions}

This study empirically examined how social factors affect smartphone switching intention and how rational and emotional factors moderate behavioral intention. When users make a switching decision, both peer influence and media influence affect switching behavioral intention, consistent with findings obtained from prior studies.

Motivated by a need to understand the moderating drivers of users' smartphone switching intention, this research incorporated switching experience and confidence in decision making as rational aspects, anticipated regret, and alternative attractiveness as emotional aspects. While analyzing the effects of these moderating variables, this study also demonstrated systematic and rigorous methodology of testing moderating effects using SEM. It showed that customers' rational factors (e.g., switching experience and confidence in decision) and customers' emotional factors (e.g., anticipated regret and alternative attractiveness) were moderating factors.

Our findings indicate that those rational and emotional factors are very significant in smartphone switching intention. Specifically, based upon the empirical analysis, we discuss the role of switching experience. Generally, if a consumer keeps using a product without switching it, this indicates that he or she is relatively satisfied with the product. Particularly, even though a consumer has switched her smartphones several times, if she is still using the same platform, it means that she has a high level of loyalty toward a certain platform. Accordingly, even with the direct encouragement of peers, the user's decision may not be shaken. Therefore, relatively formal and indirect media influence may have a greater impact on the intention of switching. Meanwhile, consumers with high switching experience imply that they were dissatisfied with the platform they used. Accordingly, peer influence can be made to form a stronger switching intention.

On the other hand, we discuss the role of confidence in decision making. Groups with high confidence in decision making also have high confidence in their ability to process external information. Accordingly, more formal external information may have a greater impact on the intention of the replacement. Meanwhile, groups with low confidence in decision making will be less confident without advice [45]. In this case, decisions are made with the help of family or friends [46]. Accordingly, peer support can help form a stronger intention to switch.

In addition, we also discuss the role of anticipated regret as following. If perceived risk level is high, consumers prefer to seek more direct information [47]. Specifically, consumers who perceive high 
anticipated regret trust information from simple but direct acquaintances more than from relatively indirect information [48].

Meanwhile, groups with low anticipated regret can be more influenced by factual and objective information provided by media than by word-of-mouth [49,50]. Therefore, media influence can affect the intention of switching more widely than peer influence.

Finally, we discuss the role of alternative attractiveness. High alternative attractiveness implies that the intention of switching is relatively high. In other words, consumers who perceive high alternative attractiveness are confident in their decision making. Accordingly, more formal media information can have a greater impact on switching intention than interpersonal information. On the other hand, direct peer pressure has a more direct and strong influence than any other sources [51]. Accordingly, consumers are more likely to be affected by peers than media, if they perceive low level of alternative attractiveness. As a result, in the case of high alternative attractiveness, media influence plays an important role in shaping short-term switching intention. On the contrary, in the case of low alternative attractiveness, peer influence plays a significant role in shaping the long-term switching intention.

\section{Implications and Limitations}

This study contains several theoretical and practical implications. Although existing post-adoption research has accepted positive constructs such as satisfaction or sustainable use, this study adopted switching behavioral intention when trying to understand smartphone switching behavior.

To illustrate, industries have recently been reorganizing around representative brands. In other words, when consumers choose their smartphones, their basic question is whether to choose Android or iPhone. Therefore, this is a switching matter, and the smartphone market is the most representative industry to look at switching behavior. Accordingly, we revealed which factors affect switching behavior.

Specifically, this study adopted social factors where switching behavior was explained by both peer and media influences and provided rigorous moderating effects. This approach will help many smartphone companies in fierce competition to lead to sustainable growth.

Nevertheless, this study deserves several limitations. First, it relates to the self-report method used in collecting data from users. For further research, the study could have been strengthened if perception-based data was complemented with objective data obtained from other sources. Second, this study empirically tested only a limited set of constructs, which is small considering the variety of those studied in other studies. Finally, considering switching is a complex decision-making process, it needs to conduct a set of experiments and quasi-experiments using specially developed Android and iOS characteristics based on experiences, complemented by in-depth research.

Author Contributions: C.-G.O. and J.P. conceived and designed the conceptualization; C.-G.O. performed the research and the analysis and completed the methodology. J.P. performed the investigation and writing and manuscript preparation. All authors contributed in discussing the research, writing parts of the paper and commenting on draft versions and finalized the paper. All authors have read and agreed to the published version of the manuscript.

Funding: This work was supported by Kyungnam University Foundation Grant, 2016.

Conflicts of Interest: The authors declare no conflict of interest.

\section{References}

1. Nikou, S.; Bouwman, H.; De Reuver, M. A consumer perspective on mobile service platforms: A conjoint analysis approach. Commun. Assoc. Inf. Syst. 2014, 34, 1409-1424. [CrossRef]

2. Scarsella, A.; Stofega, W. Worldwide Smart- phone Forecast Update, 2015-2019; IDC: Framingham, MA, USA, 2015.

3. Nysveen, H.; Pedersen, P.; Thorbjørnsen, H. Explaining intention to use mobile chat services: Moderating effects of gender. J. Consum. Mark. 2005, 22, 247-256. [CrossRef] 
4. Yi, M.Y.; Jackson, J.D.; Park, J.S.; Probst, J. Understanding information technology acceptance by individual professionals: Toward an integrative view. Inf. Manag. 2006, 43, 350-363.

5. Keaveney, S.; Parthasarathy, M. Customers switching behavior in online services: An exploratory study of the role of selected attitudinal, behavioral, and demographic Factors. J. Acad. Mark. Sci. 2001, 29, 374-390. [CrossRef]

6. Appiah, D.; Howell, K.E.; Ozuem, W.; Lancaster, G. Building resistance to brand switching during disruptions in a competitivemarket. J. Retail. Consum. Serv. 2019, 50, 249-257.

7. Keaveney, S.M. Customer switching behavior in service industries: An exploratory study. J. Mark. 1995, 59, 71-82. [CrossRef]

8. Lewis, W.; Agarwal, R.; Sambamurthy, V. Sources of influence on beliefs about information technology use: An empirical study of knowledge workers. MIS Q. 2003, 27, 657-678. [CrossRef]

9. Oh, C.G. Understanding the role of platform types and anticipated regret. J. Internet Electron. Commun. Res. 2014, 14, 1-20.

10. Boulding, W.; Ajay, K.; Richard, S.; Valarie, A.Z. A dynamic process model of service quality: From expectations to behavioral intentions. J. Mark. Res. 1993, 30, 7-27. [CrossRef]

11. Rogers, E.M. The challenge: Lessons for guidelines from the diffusion of innovations. Qual. Improv. 1995, 21, 324-328.

12. Brown, S.A.; Venkatesh, V. Model of adoption of technology in households: A baseline model test and extension incorporating household life cycle. MIS Q. 2005, 29, 399-426. [CrossRef]

13. Promotosh, B.; Sajedul, I.M. Young consumers' purchase intentions of buying green products. Unpublished Master's Dissertation, Umea University, Umea, Sweden, Spring Semester. 2011.

14. Bhattacherjee, A. Acceptance of e-commerce services: The case of electronic brokerages. IEEE Trans. Syst. Cybern. Part A Syst. Hum. 2000, 30, 411-420.

15. Karahanna, E.; Straub, D.W.; Chervany, N.L. Information technology adoption across time: A cross-sectional comparison of pre-adoption and post-adoption beliefs. MIS Q. 1999, 23, 183-213. [CrossRef]

16. Childers, T.L.; Rao, A.R. The influence of familial and peer-based reference groups on consumer decisions. J. Consum. Res. 1992, 19, 198-1211. [CrossRef]

17. Schmitz, J.; Fulk, J. Organizational colleagues, media richness, and electronic mail. Commun. Res. 1991, 18, 487-523. [CrossRef]

18. Fulk, J. Social construction of communication technology. Acad. Manag. J. 1993, 36, 921-950.

19. Hoffman, D.L.; Novak, T.P. Marketing in hypermedia computer-mediated environments: Conceptual foundations. J. Mark. 1996, 60, 50-68. [CrossRef]

20. Insabato, A.; Pannunzi, M.; Rolls, E.T.; Deco, G. Confidence related decision making. J. Neurophysiol. 2010, 104, 539-547. [CrossRef]

21. Bearden, W.O.; Hardesty, D.M.; Rose, R.L. Consumer self-confidence: Refinements in conceptualization and measurement. J. Consum. Res. 2001, 28, 121-134. [CrossRef]

22. Tsai, C.I.; Klayman, J.; Hastie, R. Effects of amount of information on judgment accuracy and confidence. Organ. Behav. Hum. Decis. Process. 2008, 107, 97-105.

23. Sun, H.; Luo, F.; London, J.; Jiao, X. Fashionable Technology, Fashion Waves, and Post-adoption Regret and Satisfaction. In Proceedings of the Thirty Fifth International Conference on Information Systems, Auckland, New Zealand, 14-17 December 2014.

24. Zeelenberg, M.; Pieters, R. A theory of regret regulation 1.0. J. Consum. Psychol. 2007, 17, 3-18. [CrossRef]

25. Zeelenberg, M. The use of crying over spilled milk: A note on the rationality and functionality of regret. Philos. Psychol. 1999, 12, 325-340. [CrossRef]

26. Zou, H.; Sun, H.; Fang, Y. Understanding Post-Adoption Regret from the Perspectives of Herding and Mindfulness. 2015, pp. 1-19. Available online: https://aisel.aisnet.org/cgi/viewcontent.cgi?article=1583\& context=icis2015 (accessed on 30 January 2020).

27. Kahneman, D.; Tversky, A. Prospect theory: An analysis of decision under risk. Econometrica 1979, 47, 263-291. [CrossRef]

28. Chang, H.J.H.; Wang, K.H.; Li, S.Y. Applying push-pull mooring to investigate channel switching behaviors. Electron. Commun. Res. Appl. 2017, 24, 50-67.

29. Yuen, B.; Azree, M.R. A socio-behavioral study of home computer users' intention to practice security. J. Appl. Soc. Psychol. 2005, 25, 234-247. 
30. Greszczuk, C.; Mughal, F.; Mathew, R. Peer influence as a driver of technological innovation: A qualitative study of clinicians' experiences and attitudes. BMJ Innov. 2018, 4, 68-74. [CrossRef]

31. Hoffman, K.; Elwin, C. The relationship between critical thinking and confidence in decision-making. Aust. J. Adv. Nurs. 2004, 22, 8-12.

32. Conner, M.; Abraham, C. Conscientiousness and the theory of planned behavior: Toward a more complete model of the antecedents of intentions and behavior. Personal. Soc. Psychol. Bull. 2001, 27, 1547-1561.

33. Shih, E.; Schau, H.J. To justify or not to justify: The role of anticipated regret on consumers' decision to upgrade technological innovations. J. Retail. 2011, 87, 242-251. [CrossRef]

34. Sharma, N.; Patterson, P.G. Switching costs, alternative attractiveness and experience as moderators of relationship commitment in professional, consumer services. Int. J. Serv. Ind. Manag. 2000, 11, 470-490. [CrossRef]

35. Ghazali, E.; Nguyen, B.; Mutum, D.S.; Mohd-Any, A.A. Constructing online switching barriers: Examining the effects of switching costs and alternative attractiveness on e-store loyalty in online pure-play retailers. Electron. Mark. 2016, 25, 157-171. [CrossRef]

36. Shih, H.; Hsu, C. Understanding the role of satisfaction in the formation of perceived switching value. Decis. Support Syst. 2014, 59, 152-162.

37. Hulland, J. Use of partial least squares (PLS) in strategic management research: A review of four recent studies. Strateg. Manag. J. 1999, 20, 195-204. [CrossRef]

38. Gefen, D.; Straub, D.W. Structural equation modeling and regression: Guidelines for research practice. Commun. AIS 2000, 4, 1-77. [CrossRef]

39. Hair, J.E.; Rolph, E.; Anderson, R.; Tatham, L.; William, C.B. Multivariatedata Analysis; Prentice Hall: Englewood Cliffs, NJ, USA, 1995.

40. Fornell, C.; Larcker, D.F. Evaluating structural equation models with unobservable variable and measurement error. J. Mark. Res. 1981, 18, 39-50. [CrossRef]

41. Kline, R.B. Principles and Practice of Structural Equation Modelling, 3rd ed.; The Guilford Press: New York, NY, USA, 2010.

42. Jöreskog, K.G.; Sörbom, D. LISREL8 User's Reference Guide; Science Software: Chicago, IL, USA, 1993.

43. Im, I.; Kim, Y.; Han, H.J. The effects of perceived risk and technology type on users acceptance of technologies. Inf. Manag. 2018, 45, 1-9.

44. Oh, C.G. The effects of anticipated regret on user's acceptance of digital convergence appliance. J. Korean Data Anal. Soc. 2012, 14, 1153-1167.

45. Lee, M.D.; Dry, M.J. Decision making and confidence given uncertain advice. Cognit. Sci. 2006, 30, $1081-1095$. [CrossRef]

46. Stankevich, A. Explaining the consumer decision-making process: Critical literature review. J. Int. Bus. Res. Mark. 2017, 2, 7-14.

47. Kusumawati, A. Evaluation of social media role as an information source in decision-making process. J. Decis. Syst. 2019, 93, 44-47.

48. Nowak, K.L.; McGloin, R. The influence of peer reviews on source credibility and purchase intention. Societies 2014, 4, 689-705. [CrossRef]

49. Ioanăs, E.; Stoica, I. Social media and its impact on consumers behavior. IJEPT 2014, 4, 295-303.

50. Hetts, J.J.; David, S.B.; David, A.A.; Faith, G.; Ariel, N. The influence of anticipated counterfactual regret on behavior. Psychol. Mark. 2000, 17, 345-368.

51. Sullivan, T.N.; Helms, S.W.; Bettencourt, A.F.; Sutherland, K.; Lotze, G.M.; Mays, S.; Wright, S.; Farrell, A.D. A qualitative study of individual and peer factors related to effective nonviolent versus aggressive responses to problem situations among adolescent with high incidence disabilities. Behav. Disord. 2012, 37, 163-178. [CrossRef]

(C) 2020 by the authors. Licensee MDPI, Basel, Switzerland. This article is an open access article distributed under the terms and conditions of the Creative Commons Attribution (CC BY) license (http://creativecommons.org/licenses/by/4.0/). 